\title{
Tourism Marketing for Sustainable Development in Phayao Province, Thailand
}

\author{
Warach Madhyamapurush $^{1}$, Chompunuch Jittithavorn ${ }^{2}$ \\ ${ }^{1}$ School of Management and Information Sciences, University of Phayao, Phayao, Thailand \\ ${ }^{2}$ College of Management, University of Phayao, Bangkok, Thailand
}

Email address:

Warachm@gmail.com (W. Madhyamapurush), chompunuchj@gmail.com (C. Jittithavorn)

\section{To cite this article:}

Warach Madhyamapurush, Chompunuch Jittithavorn. Tourism Marketing for Sustainable Development in Phayao Province, Thailand. International Journal of Hospitality \& Tourism Management. Vol. 4, No. 2, 2020, pp. 15-20. doi: 10.11648/j.ijhtm.20200402.11

Received: May 16, 2020; Accepted: August 18, 2020; Published: October 30, 2020

\begin{abstract}
Phayao is one of the northern provinces in Thailand. It has variety and unique geographical and cultural tourist attractions with few travellers' knowledge of this fact. In 2011, the province came up with such vision intended to develop tourism under the programme "Safety Agriculture and Sustainable Tourism". The local government created a great deal of tourism plans in order to support tourism activities. However, the results were not successful because those tourism plans lacked tourism marketing understanding. The purpose of this research is to develop the better understanding of tourism marketing in term of sustainable tourism development in Phayao province. Mixed methods of both qualitative and quantitative methods were employed as research methodology. Questionnaire surveys were conducted with 400 samples, which were Thai tourists. Furthermore, focus group techniques were employed with 10 experts from related fields, namely tourism, marketing, and policy making fields (from both government and private sectors). The findings of this research are focusing on three major issues: 1) Thai tourist behaviour, 2) tourism marketing mixture in Phayao province, 3) developing of tourism marketing in Phayao province. According to the Thai tourist behaviour, the results revealed the information about the tourists in the following aspects: 1) length of stay (1 day), 2) travelling cost (1700 baht), 3) activities (health tourism and soft adventure), 4) accommodation (hotel), 5) tourism resource (nature and culture). In addition tourism marketing in Phayao province should be developed as follows: 1) planning, 2) product and service development, 3) tourism network, 4) human resource development, 5) price, 6) friend-to-friend, 7) government cooperation.
\end{abstract}

Keywords: Tourism Marketing, Phayao Province, Thai Tourist Behaviour

\section{Introduction}

Nowadays, tourism is one of the most important industries for the economic development and prosperity worldwide. It has been accepted the world over that the tourism industry can help to generate revenue for the country, which ranked 13 in the top 10 key industries in many countries [1]. Moreover, tourism creates many vacation activities for those who have been working all year round.

Tourism increases purchasing power and currency exchange, which multiplies the global cash flow and employment within its own industry and related fields. As a result, this will lead to the continuous and sustainable economic development.

The major elements of tourism consist of tourists, tourist attractions, and related businesses [1]. Under these three elements, there are three components: 1) demand (personal needs of the tourist, tourist attractions and the surrounding environment), 2) supply (tourist satisfaction, the readiness of the attractions and other facilities), 3) impact (experience and knowledge gained by the tourists, income, environment, deterioration, social and economic impact) [2]. Considering the structure and elements of the tourism industry, in order to drive the industry a good management system for all is required. However, it is found that if the operation of the tourism industry is not well managed, especially in the coordination and cooperation processes. In addition, there are many tourism operators that adopt family management style or dictatorship rather than good management practice. This poses problems to the services provided to the tourists. Therefore, there is no quality control over the services, and the quality of the service facilities that would lead to tourists' 
satisfaction [3]. These problems highlight the importance for good management practices that will make the tourism industry sustainable.

Thailand has been struggling with political problems since 2006, which is the main constraint to the development of the country [4]. Still, Thailand has found the solutions to solve such problems. Tourism is one of the solutions because Thailand has a variety of tourism resources consisting of natural resources (around 60\%) and cultural resources (around 40\%) [5]. The tourism industry involves: 1) tourism activities (transportation, accommodation, restaurant), 2) tour operations, tourism destinations, tourism support (entertainment, leisure, and souvenirs), 3) other support (gas station, hospital, and supermarket), 4) tourism development and tourism employee [1].

Though traveling in Thailand is a preference of both domestic and international tourists. Thailand also offers many tourism models to serve the needs of tourists. According to Goeldner and Ritchie [1], there are 3 tourism models: 1) nature-based tourism, 2) culture-based tourism, 3) special interest tourism. The Ministry of Tourism and Sport has reported about the tourism marketing share in 2019, Thailand will have 39.7 million tourists visiting. The number of international tourists in 2019 increased to $4.24 \%$ $(39,797,406)[6]$.

Phayao is a province in the northern part of Thailand, in the region of Chiang Rai, Chiang Mai, Lampang, Phrae, and Nan provinces. Phayao is a gateway city when travelling from Bangkok to other provinces such as Chiang Rai or in the case of travelling from Nan to Chiang Mai province. In the past Phayao province was not a major tourism destination. It was the city where most travellers would stop for a rest break or to have a meal.

The governor of Phayao province during the agenda of 2006 to 2009, Mr. Thanasak Ausawanurat initiated a candle lit water activity, which is the only one in the world held in Kwan Phayao (Phayao Lake), it is a world's record at the monastery [7]. In addition, Phayao becomes better known by the Tourism Authority of Thailand's marketing campaign, so called "Unseen in Thailand". Nowadays all tourism activities are not seasonal as they once were, now an all year-round tourism calendar on the website of the Tourism Authority of Thailand. The tourism website [8] had also promoted tourism in Phayao and nearby provinces. Yet, some traditional activities and events could not be arranged for the whole year, but only important Buddhist calendar days. From this point some tourists recognise Phayao as a transit city, not a tourist destination.

Previously stated issues concerning Phayao has various types of tourist attractions, which are: 1) natural attractions such as Kwan Phayao (Phayao Lake), Phu Lanka Mountain, Phusang National Park, Phunang National Park, Dinosaur Park, Luang Mountain, Angel Cliff, 2) historical and archaeological sites such as the Cultural Hall, Phra That Chom Si Temple, King Monument, Ancient Wiang Lor, Tai Lue temple, 3) all-year-round festivals in Phayao, for example, Jewel industrial festival, Phayao New Year festival,
Tau Lue New Year, Lychee festival, Traditions merit to God, Water festival, Lantern festival [7]. These tourism attractions and activities can also attract and stimulate an increasing number of tourists to Phayao. These can be seen in Tourism statistics in 2019, the total number of tourists who have visited Phayao province has reached 656,918 which consisted of 629,677 Thai tourists and 27,241 Foreign tourists. The average cost of tourist expenditure is 1350 million baht in this year [6].

In addition, Phayao is in the mainstream of changes, according to Free Trade Agreement (FTA) and ASEAN Economic Community (AEC), travelling to ASEAN countries will be easier [7]. Phayao is one of the most important transit cities to its neighbouring border country Laos [8]. The major borders connected with three provinces are: 1) Chiang Rai, Mae Sai border (Thailand and Myanmar) and Chiang Khong border (Thailand and Lao PDR can travel to China via R3A) 2) Nan Province, Huai Kron border (Thailand and Lao PDR via R2A) and 3) Phayao, Baan Hok (Thailand and Lao PDR via R2A) [9].

Ideally tourism would be that tourists can relax, release from their stress and everyday life at their desired places and at the right time. From this point of view, tourism in Phayao supposes to fulfil tourists needs, wants and satisfaction under Phayao's context. This means that Phayao tourism would attract certain types of tourists.

This would bring good quality tourists, who are ready to convey information of Phayao tourism through WOM (Word of Mouth) and WOW (Word of Web), and revisit Phayao. It is no exaggeration that the revisit phenomena would reflect the quality of tourist attractions, which is the Phayao province itself. As a result, the quantity of the tourists should not be the main target in Phayao tourism development, the quality of the tourists and value in tourism should indeed be considered.

According to context of tourism resources in Phayao [7], it revealed that Phayao has both natural resource and cultural tourism resources along with its long history from past to present. Phayao also has many agricultural products, especially herbs and herb plantations. Its landscape and climate also suitable for people to live with an authentic lifestyle (Lanna), which is not modified like many provinces in the Northern region, this can be seen in Phayao's vision of "Safety agriculture and Sustainable Tourism". Besides, Phayao has University of Phayao, where knowledge is accumulated and transferred to communities by way of cooperation with provincial government in delivering the project of "One Province, One University" in order to develop the province.

The vision shows that Phayao is ready to be a sustainable tourism city, but the question is how to create tourists understanding and bring a quality tourist according to marketing tourism perspectives, tourists perceived and decided to travel to or within Phayao not only for transit. Tourism marketing is supposed to sort out to acquire real target tourists and to protect the province's tourism system from damages like some other provinces. Those provinces 
promoted tourism without proper marketing plan as a result attract poor quality tourists and lead to the damage of sensitive tourism resources. In addition, well-planned tourism marketing could help Phayao in implementing sustainable tourism through organised and quick responses to all tourists in any situation, not only focusing on tourists desired behaviour. Currently tourists are not behaving with the appropriate manner, they always do as they please. Nowadays, tourists are using social media networks, for example, Facebook, Four Square and Trip advisor as a source of information. Social media is one of most powerful marketing channels in influencing people to determine their trip. Online information also affects their choices in selecting destination. Unsurprisingly that Phayao also should adopt online marketing techniques as another distribution channel to attract more incoming quality tourists.

As mentioned above the researchers believe that tourism marketing is one of the most important tools to develop sustainable tourism in Phayao. Researchers intend to study behaviour of tourists who travel to Phayao, adopting many perspectives in tourism behaviour concepts by March and Woodside [10], Kotler el. al, [11], and Morrison [12]. This research has focused on both demand side, which refers to tourist behaviour, and supply side, which refers to tourist destinations, tourism agencies and supportive government bodies. The results of this study would provide tourism marketing guidelines for Phayao province, as well as propose a marketing mix model.

Furthermore, this research also adopted the perspective of Eber [13] in sustainable tourism, that it should be used to sustain and continue in developing any tourism products, cultivating good perception to tourists of tourism destinations and tourism personnel and supporting the key component of the supply side.

\section{Research Objectives}

This research aims to build tourism marketing for sustainable development of Phayao province. The research objectives are as the following:

1) to study tourists behaviour of Thai travellers in Phayao province,

2) to investigate tourism marketing techniques in Phayao province,

3) to propose the proper tourism marketing for sustainable development of Phayao province.

Research Framework

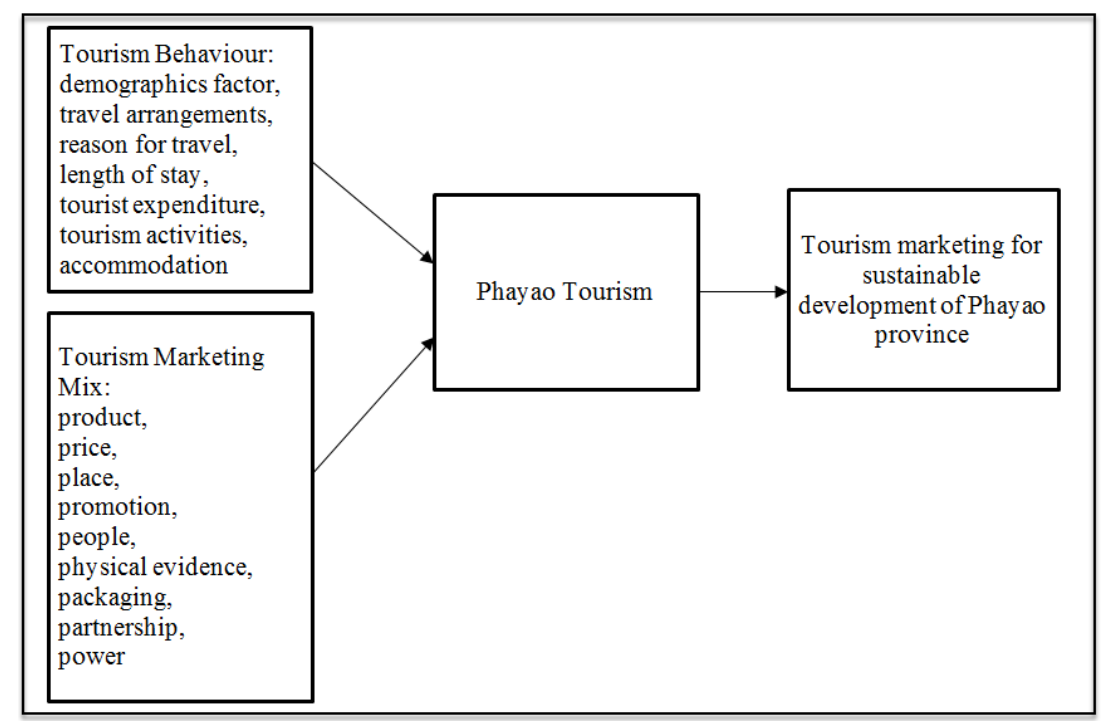

Figure 1. Research Framework.

\section{Research Methodology}

This research utilised mixed methods between quantitative and qualitative methods as research methodology. The quantitative method used questionnaire surveys with Thai tourists of 400 in sample size. It is to study the tourist behaviour and Tourism Marketing in Phayao province. In order to develop tourism marketing, the qualitative method was used by conducting a focus group with 10 experts within the tourism field, marketing field, and policy maker field (both from government and private sector).

\section{Results}

\subsection{Thai Tourist Behaviour}

Table 1. Demographics of Tourist.

\begin{tabular}{lll}
\hline Item & & Percentage \\
\hline \multirow{2}{*}{ Gender } & Female & 70.00 \\
& Male & 30.00 \\
\multirow{2}{*}{ Age } & $40-49$ Years & 34.50 \\
& $50-59$ Years & 31.50 \\
& 30-39 Years & 22.50 \\
& Less than 30 Years & 10.00 \\
& 60 Years and over & 01.50 \\
\hline
\end{tabular}




\begin{tabular}{lll}
\hline Item & & Percentage \\
\hline \multirow{3}{*}{ Occupation } & Government officer & 40.00 \\
& Businessman & 19.50 \\
& House mate & 18.00 \\
& Private company employee & 17.50 \\
Revenue & Unemployed & 05.00 \\
& $10,001-20,000$ Baht & 57.50 \\
& 20,0001 - 30,000 Baht & 33.50 \\
Marital status & Less than 10,000 Baht & 05.50 \\
& More than 30,000 Baht & 03.50 \\
& Married & 70.00 \\
& Single & 18.50 \\
\hline
\end{tabular}

Demographics: 70 percent of tourists are female, most tourists age is $40-49$ years as 34.5 percent, half of the samples have an average income 10,001 - 20,000 THB (333 - 666 USD), and almost 70 percent of the travellers are married.

Table 2. Thai Tourism behaviour

\begin{tabular}{|c|c|c|}
\hline Item & & Percentage \\
\hline \multirow{4}{*}{ Cost of Travel } & Under 2,000 Baht & 57.50 \\
\hline & $4,001-6,000$ Baht & 33.50 \\
\hline & $2,001-4,000$ Baht & 05.50 \\
\hline & More than 6,000 Baht & 03.50 \\
\hline \multirow{4}{*}{$\begin{array}{l}\text { Price comparison of } \\
\text { Products and } \\
\text { Services }\end{array}$} & Reasonable accommodation cost & 40.00 \\
\hline & Compare the price as value & 30.00 \\
\hline & Reasonable tourism cost & 20.00 \\
\hline & Reasonable activities cost & 00.10 \\
\hline \multirow{3}{*}{ Facilitator Tourism } & Relative & 36.50 \\
\hline & Family & 26.50 \\
\hline & Self-travel/ friend group & 20.50 \\
\hline \multirow{4}{*}{ Group conformance } & With Companies & 16.50 \\
\hline & By spouse / family & 41.50 \\
\hline & Decide for yourself & 34.50 \\
\hline & By friend group & 24.00 \\
\hline \multirow{3}{*}{ Reason for Travelling } & $\begin{array}{l}\text { There are beautiful tourist } \\
\text { attractions }\end{array}$ & 32.50 \\
\hline & High tourism safety & 26.50 \\
\hline & $\begin{array}{l}\text { Cost of Travelling (Cheap than } \\
\text { other destination) }\end{array}$ & 23.50 \\
\hline \multirow{3}{*}{ Information Chanel } & Able to travel all year round & 17.50 \\
\hline & $\begin{array}{l}\text { Online media (via Facebook / line } \\
\text { / Instagram / tourist website) }\end{array}$ & 99.00 \\
\hline & $\begin{array}{l}\text { Offline media (Newspaper / } \\
\text { Magazine) }\end{array}$ & 01.00 \\
\hline \multirow{3}{*}{$\begin{array}{l}\text { Tourism } \\
\text { characteristics }\end{array}$} & Traveling with family & 50.00 \\
\hline & Travel with friends & 40.00 \\
\hline & Travel alone & 10.00 \\
\hline \multirow{4}{*}{ Travel cost categories } & Traveling & 40.00 \\
\hline & Accommodation & 30.00 \\
\hline & Food and beverage & 20.00 \\
\hline & Tourism Activities & 10.00 \\
\hline \multirow[t]{2}{*}{ Planning for Travel } & $\begin{array}{l}\text { No Planning (know the } \\
\text { destination) }\end{array}$ & 60.00 \\
\hline & Planning (unknown destination) & 40.00 \\
\hline \multirow{3}{*}{ Traveling Duration } & $1-3$ Day/s & 92.50 \\
\hline & 4-6 Days & 06.00 \\
\hline & More than 7 Days & 01.50 \\
\hline \multirow{3}{*}{ Tourism Resource } & History park and Local Museum & 38.50 \\
\hline & Cultural and Local Event & 35.00 \\
\hline & Natural and Agro-tourism & 26.50 \\
\hline
\end{tabular}

Thai tourism behaviour: 57.5 percent of the cost of travel are under 2,000 THB (66 USD), 40 percent of price comparison of product and service are reasonable accommodation, travel arrangements: 90 percent travel by themselves (they do not purchase any package tour from travel agency), search information before travel 70 percent, 99 percent reach all data through internet, travelling with family 50 percent and with friends 40 percent. Most of tourists booked their trip 1-2 weeks prior by searching data on internet but make a reservation by phone. 50 percent of the respondents are repeat visitors and the reasons for revisit are their impressions with the tourist destinations, need to travel at all various styles of tourism in Phayao and low cost of travel.

Reasons to travel in Phayao: tourists interested in cultural tourism and traditional events, natural resources for example, Phu Lanka authentic way of life as previously mentioned, Phayao has supported sustainable tourism.

Length of stay: Most of them spend only one day during cultural events and Phayao also has such an event, taking 1-2 days (92.5 Percent)

Tourist expenditure: tourist spend around 1,700 THB (60 USD) per person each time when traveling to Phayao which are, travel 40 percent, food and beverage 20 percent, accommodation 30 percent and for activities or souvenirs 10 percent.

Tourism activities: Health tourism and adventure are the most popular activities. This research has separated tourists into 2 groups, tourists of 15-35 years choose adventure tourism as an activity then cultural tourism but groups of more 35 years choose health tourism first then religion tourism.

Accommodation: Tourist prefer boutique hotels which is not expensive, and several boutique hotels has also increased in order to respond to tourists' lifestyles.

Tourism resources: Thai tourists interested in natural and cultural tourism because they are interested in natural and cultural preservation (73.5 percent), need to promote natural and cultural resources (60 percent) and spend money to improve economic status of the local people.

\subsection{Tourism Marketing Mix for Phayao Province}

Table 3. Tourism marketing mix for Phayao province.

\begin{tabular}{llll}
\hline Tourism Marketing Mix & $\boldsymbol{X}$ & S. D. & Important \\
\hline Product & 3.62 & .766 & Most \\
Price & 3.63 & .704 & Most \\
Place & 3.82 & .740 & Most \\
Promotion & 3.74 & .760 & Most \\
People & 3.71 & .760 & Most \\
Physical evidence and & 3.70 & .792 & Most \\
presentation & 3.54 & .702 & Most \\
Packaging & 3.76 & .750 & Most \\
Partnership & 3.68 & .743 & Most \\
Power & & &
\end{tabular}

Product $($ Mean $=3.62, \mathrm{SD}=0.766)$ : Relating to tourist attraction must link all destination because of distance of distance of each location. Phayao is also one of the Northern traditional cities, creating timeline story will attract tourist more. For cultural tourist destinations, billboards with history 
or signage is necessary in order to provide more information to tourists.

Price $($ Mean $=3.63, \mathrm{SD}=0.704)$ : All tourism agencies have a common comment that price determination should not be much higher than sensible price. Furthermore, Thai tourists like to negotiate a lower price, when using discounted prices Thai tourists may feel that they get a good quality product with a reasonable price.

Place $($ Mean $=3.82, \mathrm{SD}=0.740)$ : Tour operator, the bestselling channel is the internet, website and E-mail so this is one of most important channels, but travel agents are also important because some tourists do not rely on the internet, they need to be assured that the tourist agency really exist.

Promotion $($ Mean $=3.74, \mathrm{SD}=0.760)$ : Tour operator should not give a discount rate to tourists when they are not asking to and cost of travel in Phayao is not so high comparing to other provinces in Thailand.

People $($ Mean $=3.71, \mathrm{SD}=0.760)$ : Tour operator, need to improve their skills and service quality to create lasting tourists' impressions. Local tour guides should play an important role in taking tourists to any destination.

Physical evidence $($ Mean $=3.70, \mathrm{SD}=0.792)$ : Tourist destinations must arrange in identity of Phayao through Lanna architecture.

Packaging $($ Mean $=3.54, \mathrm{SD}=0.702)$ : Phayao tourism should include service, tourism destination, tourist activity in a package that they can travel on their own, tour guide may be excluded.

Partnership $($ Mean $=3.76, \quad$ SD $=0.750)$ : Creating partnerships among tourist agencies is needed, not only to serve tourists satisfaction but to share ideas in developing plans for the tourism system.

Power $($ Mean $=3.68, \mathrm{SD}=0.743)$ : Travel agencies should play an important role in cooperating with others and attend tourism activities arrange by the government to create a strong cohesion of tourism agencies in Phayao.

\subsection{The Key Concepts of Tourism Marketing Development in Phayao Province}

Marketing plan: Tourism marketing is teamwork between many partners and the cooperation is highly needed so the related organisations can determine mutual plans, as to avoid any overlap responsibilities and work with a broad view and team actions. The Three Marketing Plans:

Normal Situation: Work with tourism product activities as Cultural and Historical parks. Segmentation with mass tourism. Operate tourism with private sector.

Quality Situation: Work with tourism product activities as Cultural and historical park. Segmentation with individual tourism (Mid-End tourist - High-End tourist). Operate tourism with the community sector.

Crisis: Work with tourism product activities as Natural and Historical Parks. Segmentation with individual tourism (Mid Tourist - Mid-End tourist). Operate tourism with Government sector.

Product and Service Development: Not only to improve product and service but also study tourist behaviour in order to fulfil their needs. Protecting the identity of Phayao is also important point to consider.

Tourism networking: Phayao tourism is supported by many organisations with a long-term plan so contributing through tourism network is a key factor. The Thai Chamber of Commerce (Phayao office) will be the centre of coordinated marketing activities with members.

Human Resource Development: Especially service in mind, to satisfy tourist needs and this program should provide by academic institutions through training programs.

Price: Determine reasonable prices comparable to other advertising medias because Thai tourists will check the price on the internet before making a travel decision.

Friend-to-Friend Marketing: means a marketing response with customer care, as with friends. Thai tourists are attracted to quality of service other than cost of travel.

Cooperating with government: Provincial level agencies may not communicate with tourists to understand culture and category of tourism, coordinate with Public Government in conducting a marketing plan that provides the correct perception of tourism.

Model of Tourism Marketing have a new concept "3 Musts: Travel, Eat and Rest" Because Tourism in Phayao Province found that it has a lot of potential in tourism. This will cause tourists to be confused in choosing the type of tourism or tourism activities. A limited time Tourists need only one pleasing tourist activity and then connect to other tourist destinations or set tourism routes for tourists with half a day, day and DIY routes (The designated all tourist routes will have important tourist attractions in Phayao. Including restaurants for tourism and accommodation while traveling.)

"3 Musts: Travel, Eat and Rest" concept are 1) Travel: Kwan Phayao is the third most frequently visited lake in Thailand and have various fish and candle light water activity, which is the only one in the world held in Kwan Phayao and was the location of the world's record at the monastery. Tai Lue culture originated in Xishuangbanna, China, more than 230 years ago. 2) Eat: Phayao Province has local fisheries in Kwan Phayao. One local delicacy made famous is pickled fish (Pla som in Thai) and 3) Phu Langka, Phayao is top 5 of the provinces with the best weather in Thailand $(\mathrm{O} 2)$.

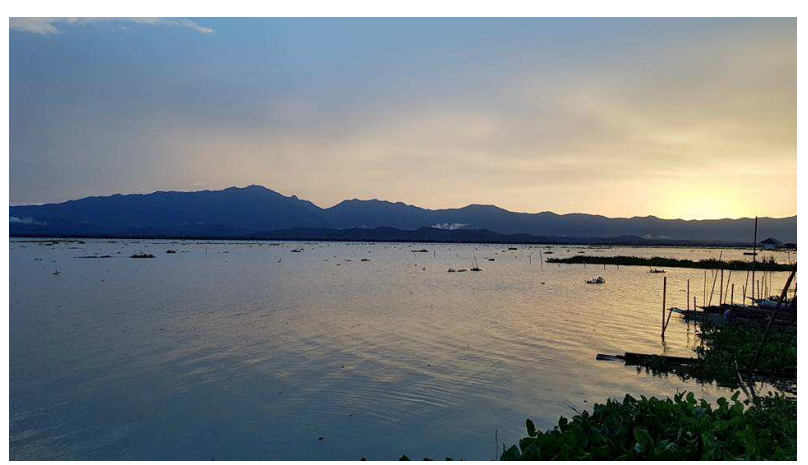

Figure 2. Kwan Phayao (Phayao Lake). 


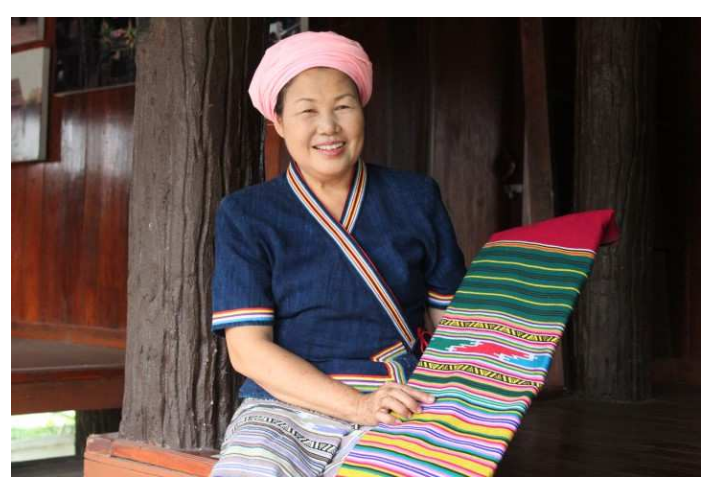

Figure 3. Tai Lue Culture.

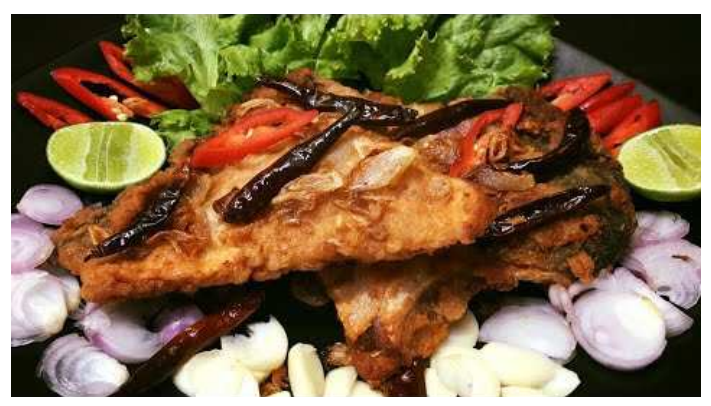

Figure 4 Food from pickled fish (Pla Som in Thai).

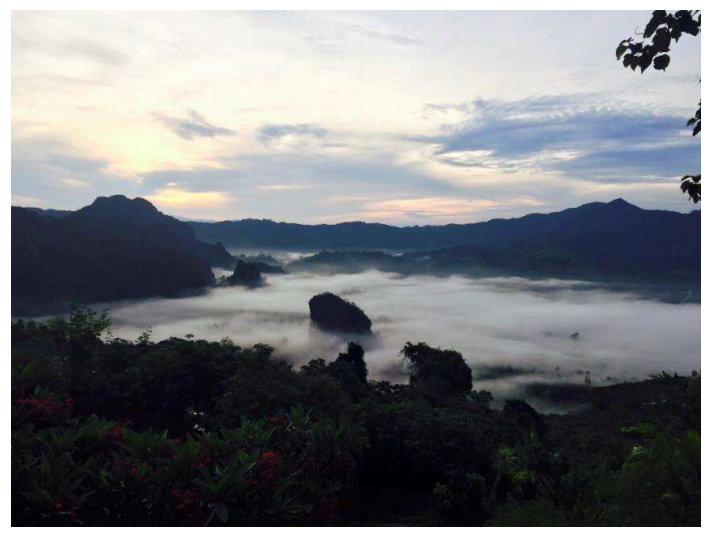

Figure 5. Phu Langka, Phayao.

\section{Conclusion and Recommendations}

To develop tourism marketing for sustainable development in Phayao province, cooperation with public and private agencies, also academic institutions is required. A sense of teamwork among these agencies is required, especially for supply side which are accommodation, restaurants, souvenir shops, tourist attractions, travel agencies. As for the support side which are provincial offices, local government, national parks office, provincial cultural offices, sports and tourism office, academic institutions have to determine mutual marketing strategy to share all responsibilities and to avoid some conflicts among these agencies with no intervention. A 360-degree data system in tourism is also needed for all partners and tourists which may use this data to search and plan their schedule as they desired (DIY Marketing).

\section{References}

[1] Goeldner, Charles R. and Ritchie, J. R. Brent. 2009. Tourism: Principles, Practices, Philosophies. 11th edition. New York: John Wiley \& Sons Inc.

[2] Madhyamapurush, Warach. 2019. Structure of Tourism System, Journal of Thai Hospitality \& Tourism (January June 2019) Vol. 14 No. 1 (2019).

[3] Westcott, M. (Ed.). 2019. Introduction to Tourism and Hospitality in B. C. Victoria, B. C.: BC campus. Retrieved from https://opentextbc.ca/introtourism/.

[4] Sawasdee, Siripan Nogsuan. (2006). Thai Political Parties in the Age of Reform. Institute of Public Policy Studies, P. Press Co., Ltd., Bangkok.

[5] Sharafuddin, Mohamed Ali. 2015. Types of Tourism in Thailand. e-Review of Tourism Research (eRTR), Vol. 12, No. 3/4, 2015 Retrieved from http://ertr.tamu.edu.

[6] Tourism Statistics 2019, 2020. Ministry of Tourism and Sports Retrieved from http://www.mots.go.th.

[7] Tourism Activities, 2019. Phayao. Retrieved from http://www.phayao.go.th.

[8] See and Do, Phayao, 2019. Tourism Authority of Thailand. Retrieved from http://thai.tourismthailand.org.

[9] Statistics, 2019. Immigration Bureau. Retrieved from https://www.immigration.go.th/immigration_stats.

[10] March, Roger St George and Woodside, Arch G. 2005. Tourism Behavior: Travelers'.

[11] Kotler, Philip, Bowen, John T., and Makens, James C. 2006. Marketing for Hospitality and Tourism. 4th edition. USA: Prentice Hall.

[12] Morrison, Alastair M. 2001. Hospitality and Travel Marketing. 3rd edition. USA: Delmar.

[13] Eber, Lucille. 1993. Brundtland report. London: Pergamen Press Ltd. 